\title{
A PERCEPÇÃO DOS AGENTES ECONÔMICOS SOBRE O NOVO PLANO DE DESENVOLVIMENTO ECONÔMICO, COM FOCO EM ATRAÇÃO DE INVESTIMENTOS PRODUTIVOS PARA A REGIÃO METROPOLITANA DE BRASÍLIA
}

\section{ARTIGO ORIGINAL}

CARVALHO, Rogério Galvão de ${ }^{1}$, CASADIO, Maxwell Anderson do Prado², SOUZA, Gabriel Luiz Lino de ${ }^{3}$

CARVALHO, Rogério Galvão de. CASADIO, Maxwell Anderson do Prado. SOUZA, Gabriel Luiz Lino de. A percepção dos agentes econômicos sobre o novo plano de desenvolvimento econômico, com foco em atração de investimentos produtivos para a região metropolitana de Brasília. Revista Científica Multidisciplinar Núcleo do Conhecimento. Ano: 06, Ed. 08, Vol. 02, pp. 81-96. Agosto 2021. ISSN: 2448-0959, Link de acesso:

https://www.nucleodoconhecimento.com.br/ciencias-sociais/atracao-de-

investimentos, DOI: 10.32749/nucleodoconhecimento.com.br/cienciassociais/atracao-de-investimentos

\section{RESUMO}

Há indícios que os programas em vigor para gerar desenvolvimento econômico na região metropolitana de Brasília estão dando baixos retornos, principalmente os que tentam promover investimentos. Assim o governo vê necessidade em elaborar uma nova política pública, que coordene todos os agentes econômicos envolvidos para

\footnotetext{
${ }^{1}$ Doutorado em andamento em Ciências Empresariais e Sociais. Universidad de Ciencias Empresariales y Sociales, UCES, Argentina. Mestrado em Economia. Universidade Católica de Brasília (Conceito CAPES 6), UCB/DF, Brasil. Especialização em Especialização em Direito Público. Centro Universitário Estácio Brasília, Estácio Brasília, Brasil. Graduação em Bacharelado em Economia. Centro Universitário de Brasília, UniCEUB, Brasil.

${ }^{2}$ Graduado em Ciências Econômicas pela Universidade de Brasília.

${ }^{3}$ Graduando em Ciências Econômicas (UnB).
}

RC: 93520

Disponível em: https://www.nucleodoconhecimento.com.br/ciencias-sociais/atracaode-investimentos 
esse fim. Porém ainda no começo da elaboração da nova política de desenvolvimento surge a dúvida: Como os agentes do governo, setor produtivo e pesquisadores do Distrito Federal enxergam a formulação de um novo plano de desenvolvimento? Assim, o presente trabalho consiste em fazer uma consulta a alguns desses agentes e colher suas percepções acerca de 1) O nível de maturidade das políticas públicas voltadas para o desenvolvimento socioeconômico, em Brasília nos últimos tempos; 2) O grau importância de uma política pública específica para esse fim; e 3) A satisfação com relação as diretrizes pretendidas para o Plano de Desenvolvimento Econômico com foco em Atração de Investimentos Produtivos. Assim, com essa pesquisa descobrimos se, na percepção de seus agentes econômicos, a referida política pública possui as características necessárias e suficientes para transformar a Região Metropolitana de Brasília numa área nacional de atração de investimentos e para tornar seu crescimento menos condicionado aos gastos do governo.

Palavras-chave: região metropolitana de Brasília, desenvolvimento regional, Promoção de Investimentos.

\section{INTRODUÇÃO}

É de conhecimento público que a população de Brasília é uma das maiores do país, hoje em torno de 3 milhões de habitantes, de acordo com o Instituto Brasileiro de Geografia e Estatística (IBGE), ela teve, no período de um ano, entre 2018 e 2019, um crescimento populacional de 1,36\% (um vírgula trinta e seis pontos percentuais). Esse é um crescimento populacional bem maior do que a média nacional de 0,8\% (zero vírgula oito pontos percentuais) no mesmo período.

Se incluirmos a região do entorno do Distrito Federal, ou seja, a Região Metropolitana de Brasília essa população se aproxima de 4,1 milhões de habitantes. Além disso, ela (com apenas 60 anos de existência) já é uma das regiões mais populosas do Brasil. Nas últimas décadas, ainda de acordo com o senso do IBGE, 
percebe-se que essa região metropolitana saiu da $9^{a}$ (nona) para a $4^{a}$ (quarta) Região Metropolitana mais populosa do país, perdendo apenas para as Regiões Metropolitanas de São Paulo, do Rio de Janeiro e de Belo Horizonte, como registram Carvalho; Leal e Souza (2021).

A Região Metropolitana de Brasília é conhecida como RIDE, Região integrada de desenvolvimento que, na verdade, é uma área análoga às regiões metropolitanas brasileiras, porém, como é situada em mais de uma unidade federativa do território brasileiro, nesse caso, Distrito Federal (DF), Minas Gerais (MG) e Goiás (GO), recebe o nome de RIDE-DF.

Por outro lado, a variação do PIB do Distrito Federal, nos últimos 10 (dez) anos, provavelmente devido à crise econômica recente, visivelmente não acompanhou o crescimento populacional. Nota-se, com o crescimento populacional muito rápido dessa região, mais acentuado do que a maioria dos outros estados, associado ao mau comportamento da taxa de crescimento do PIB, ceteris paribus, que haveria, num futuro próximo, um fatídico colapso no desenvolvimento econômico, em especial na prestação de serviços públicos, conforme já foi constatado em Carvalho; Leal e Souza (2021).

Uma vez que a arrecadação é um percentual do PIB, esses serviços públicos também entrariam em colapso, com o passar do tempo, porque essa arrecadação seria relativamente menor a cada ano. Dessa forma fica nítida a necessidade de haver uma política pública assertiva, voltada especificamente para minimizar os aspectos negativos desse problema.

Nesses termos, para que haja a minimização do problema socioeconômico, é importante, de acordo com a literatura sobre o assunto, que haja uma correta formulação de política pública específica para equacionar a produção e o consumo adequando-os ao ritmo do crescimento populacional, a fim de se evitar o referido colapso.

RC: 93520

Disponível em: https://www.nucleodoconhecimento.com.br/ciencias-sociais/atracaode-investimentos 
Essa pesquisa pretende investigar se Brasília reúne as características para se tornar em âmbito nacional uma região de atração e investimentos produtivos, ou seja, numa área nacional de referência para o destino de empreendimentos privados, especialmente externos, levando-se em conta a opinião dos agentes econômicos regionais.

Para iniciar a avaliação das características de Brasília e da maturidade das políticas de atração de investimentos produtivos, para essa transformação, entendemos que o referencial teórico adequado para esse caso é a teoria econômica de Clusters, conhecida no Brasil como a de Arranjos Produtivos Locais (APLs), e a teoria de economia regional, em especial os modelos de Von Thunen e o de Dixit-Siglitz.

A Política Pública que está sendo formulada em Brasília, pelo governo local teve como base, além do referencial teórico adequado, o modelo chinês de política pública de atração de investimentos, adotado no Vale do Rio das Pérolas, que transformou, em 30 anos, por exemplo, a cidade de Shenzhen, que era praticamente uma aldeia de pescadores, na cidade inteligente mais importante do planeta, uma espécie de adaptação do modelo econômico de Von Thunem, que de acordo com os estudos realizados pelo governo de Brasília, a proposta de política pública, se demonstrou bastante aderente às caraterísticas da região metropolitana de Brasília.

É fundamental respeitar as idiossincrasias da Região Metropolitana de Brasília, para que o processo de elaboração, formulação, implantação e acompanhamento (monitoramento, avaliação, análise dos resultados e ajustes) de acordo com as premissas dos técnicos desse governo para que essa política pública corretiva seja mais adequada à realidade de Brasília, em especial no que diz respeito aos empreendimentos intensivos em capital.

As características de Brasília podem ser, de acordo com esse plano, propícias para transformá-la nessa área nacional de destino de investimentos produtivos. De acordo com o IBGE, o Distrito Federal tem, por exemplo, uma mediana de escolaridade da população muito superior do que a média nacional, a obtenção da RC: 93520

Disponível em: https://www.nucleodoconhecimento.com.br/ciencias-sociais/atracaode-investimentos 
internet também é muito mais além da média nacional. Além disso, ele engloba as sedes do comando dos três poderes da União e das embaixadas dos países que têm associação diplomática com o Brasil.

Ainda que tenha um crescimento populacional acima da média e atualmente ocupe o $4^{\circ}$ (quarto) lugar na lista das mais populares Regiões Metropolitanas, ela contém uma das menores densidades demográfica, $74,45 \mathrm{hab} / \mathrm{km}^{2}$ da mesma lista. Outro privilégio competitivo é a proximidade de Grandes

Centros Produtivos (Anápolis, Goiânia, Formosa, Unaí, Catalão, Cristalina, Catalão, Uberlândia, Uberaba, Araguari, João Pinheiro, Paracatu e outros).

Outro ponto a ser visto como positivo é a crescente interligada de duas regiões metropolitanas (Goiânia e Brasília) e seus arredores, denominado como eixo Goiânia-Anápolis-Brasília, que é atualmente, segundo os dados do IBGE, uma das regiões que tem mais crescido no Brasil, com uma população que se aproxima de 7,5 (sete vírgula cinco) milhões de habitantes.

Há projeções de que na próxima década a conurbação, dessa região, se preencheria. As cidades são interligadas particularmente pela rodovia BR-060, também há voos diretos entre Goiânia e Brasília e o planejamento de uma ferrovia de transporte de passageiros de Brasília a Goiânia, tal estudos técnicos de possibilidade foram realizados pela ANTT (Agência Nacional de Transportes Terrestres), em junho de 2016, cujo valor orçado era de $\mathrm{R} \$ 7,5$ bilhões de Reais.

O Distrito Federal se destaca, dos demais estados, em diversos indicadores de competitividade econômica, pois tem melhores médias que a nacional em oito, dos dez pilares do Ranking de Competividade dos Estados. Em alguns dos pilares o DF tem posição de destaque. No de Capital Humano, por exemplo, ele ficou na $2^{\mathrm{a}}$ (segunda) colocação e em Sustentabilidade Social na 6ª (sexta) colocação.

RC: 93520

Disponível em: https://www.nucleodoconhecimento.com.br/ciencias-sociais/atracaode-investimentos 
Um fator crítico para avaliarmos o potencial de crescimento de uma região ou Estado é a disponibilidade de mão de obra, considerando tanto o tamanho do contingente disponível quanto sua qualificação e a expectativa de crescimento. Nestes quesitos, o DF mostra grande vantagem competitiva. A parcela da população em idade ativa (15 a 64 anos) no DF é a $72,5 \%$, (setenta e dois vírgula cinco pontos percentuais) é a mais alta entre todos os Estados, outra vantagem.

$\mathrm{Na}$ década de 1970, o delta do rio ao norte do território de Hong Kong era uma região agrícola, a cidade de Shenzhen tinha 30.000 (trinta mil) habitantes. Em 1979, o governo chinês, criou quatro Zonas Econômicas Especiais com a intenção de atrair investimentos estrangeiros diretos e incentivar a iniciativa privada.

A designação de Shenzhen como uma Zona Econômica Especial foi um movimento estratégico que teve impacto imediato no Delta do Rio das Pérolas. Vários fatores ajudaram a contribuir para a ascensão meteórica da região: (1) proximidade com o setor financeiro de Hong Kong; (2) um porto marítimo de classe mundial; (3) uma enorme mão de obra barata; (4) terras baratas e abundantes; e (5) poucos impedimentos regulatórios para empresas em rápido crescimento.

Nas duas décadas subsequentes, o PIB da região cresceu mais de 10 vezes e a urbanização, reforçada por projetos de infraestrutura de grande escala, começou fortemente. O Delta do Rio das Pérolas cresce e hoje está se tornando a maior região urbana contígua do mundo.

De acordo com as diretrizes do Novo plano de desenvolvimento econômico, formulado pelo governo do Distrito Federal, pelas características da região metropolitana de Brasília, de certa forma, guardadas as devidas proporções, eles puderam se inspirar nesse modelo chinês, no que diz respeito à elaboração e implantação dos programas, projetos, ações e parcerias com o setor produtivo e a sociedade civil, oriundas do novo plano de desenvolvimento econômico. Nesse sentido faz-se necessário entender: Como os agentes do governo, setor produtivo e 
pesquisadores do Distrito Federal enxergam a formulação de um novo plano de desenvolvimento?

Um ponto relevante que tratou a pesquisa de opinião eletiva (com representantes do setor produtivo, da sociedade civil e do governo), foi investigar se Brasília, de acordo com os agentes econômicos locais pesquisados, reúne as características para se transformar numa área nacional de atração de investimentos privados do Brasil por intermédio dos aspectos seguintes: 1) legislação; 2) Potenciais Arranjos Produtivos Locais; 3) Vantagens Competitivas; 4) Ecossistema da Economia da Inovação; 5) Logística; 6) Educação; e (7) Ambiente de Negócios.

Outra questão que se revelou extremamente importante foi identificar a percepção dos agentes econômicos sobre a eficiência das antigas políticas públicas de desenvolvimento econômico e do novo plano de desenvolvimento econômico com foco em atração de investimentos produtivos, cujas diretrizes tem como premissa: (1) fomento dos arranjos produtivos locais; (2) aprimoramento do ecossistema de economia da inovação; e (3) investimentos nos setores de economia criativa e circular, para transformar o Distrito Federal numa relevante área de interesse de investimentos e empreendimentos privados do Brasil.

\section{REFERENCIAL TEÓRICO}

Taxas de crescimento sem precedentes históricos têm sido frequentes a partir da segunda metade do século $\mathrm{XX}$, os milagres econômicos, que levaram à emergência e ao rápido desenvolvimento econômico de países em várias regiões do mundo. $\mathrm{O}$ Japão foi um dos primeiros, seguido da Coreia do Sul, de Taiwan, do Brasil particularmente nos anos sessenta, e outros no Sudeste Asiático. Hoje em dia temos China, Índia e Vietnã compondo esse grupo de países.

Conforme salientado por Paulino (2020) o Brasil também passou por um chamado milagre econômico entre os anos de 1968 até 1973, conhecido como a época da linha dura da ditadura. E, como observado por Stough et al (2014), este fenômeno

RC: 93520

Disponível em: https://www.nucleodoconhecimento.com.br/ciencias-sociais/atracaode-investimentos 
se replica de forma parecida em regiões dentro de países, conhecidos como aglomerados produtivos que se concentram em determinado espaço geográfico. Possivelmente o exemplo mais conhecido deles seja o Vale do Silício, no Sul do Estado da Califórnia, onde é possível encontrar as sedes de muitas empresas em Comunicação e Tecnologia da Informação (TIC) e áreas afins.

Porém, contém, pelo mundo, inúmeros outros aglomerados produtivos, como por exemplo: os que são localizados no Delta do Rio das Pérolas no Sul da China (Shenzhen, Dongguan, Zhuhai, etc.), ou o de Bangalore na Índia, ou ainda o de São José dos Campos no Brasil. Não se tem dúvidas que eles estão correlacionados, motivo pela qual é fundamental a identificação das oportunidades para o fomento de aglomerados produtivos como política pública visando 0 desenvolvimento econômico, tanto na sua dimensão nacional como na regional.

Os benefícios, advindos dos aglomerados produtivos, vêm sendo analisados desde Alfred Marshall (1890). Estão associados ao crescimento de produtividade como consequência da aglutinação de agentes econômicos e empresas em um mesmo ambiente geográfico. Fujita et al (1999), interpretando Marshall, distinguem três tipos de economias de aglomeração: 1) externalidades do conhecimento; 2) adensamento do mercado de trabalho; e 3) proximidade geográfico.

O que se relaciona às "externalidades do conhecimento" (em inglês, "knowledge spillovers"), possui um mecanismo que faz com que as ideias geradas no aglomerado possam ser apropriadas por outros integrantes sem custo para ninguém e benefícios para todos.

O segundo está associado ao adensamento do mercado de trabalho (em habilidades específicas) que é também benéfico para todos os envolvidos. Por último, a proximidade geográfica das empresas que facilita o funcionamento das cadeias produtivas integradas. 
Estas economias de aglomeração operam também para atrair novos agentes e empresas, produzindo uma dinâmica de crescimento para todo o aglomerado. A visão original de Marshall conduziu uma série de conceitos teóricos e empíricos relacionados, como: cadeias produtivas, distritos industriais, tecno polos ou parques científicos-tecnológicos, clusters e, no Brasil, arranjos produtivos locais (APLs). De acordo com Leme et al (2019) a terminologia de arranjos produtivos locais pode se usada inclusive em contexto do agronegócio, visto a integração do sistema produtivo.

Clusters industriais, de acordo com Porter (1990, 1998), são concentrações geográficas de empresas e instituições interconectadas que operam em setor específico. Nesta ampla definição se incluem relações entre empresas semelhantes que compartilham recursos comuns, relações entre empresas que fazem parte de uma cadeia produtiva, participação de agências governamentais, de instituições de pesquisa, etc.

Com a globalização a importância das vantagens comparativas geográficas fica em segundo plano e a valorização das vantagens competitivas, passa a ser mais relevante. A Vantagem competitiva necessita da existência de um ambiente propício para o empreendedorismo, em particular do ecossistema de da economia de inovação. O processo de globalização econômica está umbilicalmente ligada ao processo de globalização das informações, segundo Lima (2020) o processo de aceleramento da informatização se dá no fim do século XX e pode ser visto pelo início da disseminação de computadores pessoais.

Nos últimos 20 (vinte) anos, a conjuntura econômica internacional, mostra que a concorrência entre países e empresas é cada vez mais aguda e a competividade corresponde à capacidade de inovação. Nesse cenário, o fomento de clusters tem se firmado como uma importante estratégia de política pública para o desenvolvimento e de inserção internacional, especialmente em relação a empresas de porte pequeno e médio.

RC: 93520

Disponível em: https://www.nucleodoconhecimento.com.br/ciencias-sociais/atracaode-investimentos 
A União Europeia tem se destacado nisso. Tanto o fomento de clusters, como a a estratégia de especializações inteligentes, são pilares dessa política pública industrial. Uma das inciativas, de interesse para a cooperação internacional com outros países, é a Plataforma Colaborativa em Clusters. Até meados da segunda década do século XXI, a Plataforma manteve cooperação formal com o Grupo de Trabalho Permanente das APL (GTP APL) do Ministério de Indústria, Comércio Exterior e Serviços (MDIC).

Arranjos produtivos locais, APLs, em maior ou menos grau, são de acordo com Cassiolato e Lastres (2004) Agentes econômicos localizados numa região específica cujo foco da atividade econômica conjunta apresentem vínculos que envolvem a participação e a interação de empresas (produtoras de bens e serviços finais, ou fornecedoras de insumos e equipamentos, ou prestadoras de consultoria e serviços, ou comercializadoras, ou clientes, entre outros) e suas variadas formas de representação e associação.

Além disso, eles podem incluir dependendo do grau de maturidade do APL, também diversas outras organizações públicas e privadas voltadas para: formação e capacitação de recursos humanos, como escolas técnicas e universidades; pesquisa, desenvolvimento e engenharia; política, promoção e financiamento.

Este conceito, introduzido pela Redesist em 1997, teve grande aceitação e em poucos anos passou a ser adotado por instituições públicas voltadas à promoção da inovação e do desenvolvimento industrial, como a FINEP, o SEBRAE e o BNDES.

Em 2004, constitui-se, no atual Ministério da Economia, uma iniciativa para promoção e a formulação de políticas públicas voltadas para os APLs com a participação de diferentes órgãos de governo, que adota uma definição mais simples para APLs, segundo o qual constitui um número considerável de empreendimentos e de indivíduos que operam em torno de uma atividade produtiva que predomina e que compartilha formas observadas de colaboração e algum método de governança, incluindo grandes, médias e pequenas empresas.

RC: 93520

Disponível em: https://www.nucleodoconhecimento.com.br/ciencias-sociais/atracaode-investimentos 
O reconhecimento da existência de um APL se dá a partir de quatro variáveis principais: 1) a concentração setorial de empresas no território; 2) a concentração de indivíduos ocupados em atividades produtivas relacionadas com o setor de modelo do APL; 3) a cooperação entre os atores participantes do arranjo (empreendedores e demais participantes) em busca de maior concorrência; e 4) a existência de mecanismos de governança.

De acordo com a "Carta de Torremolinos" do Conselho da Europa (União Europeia, 1983), o ordenamento do território é a expressão espacial das políticas públicas e para o desenvolvimento equilibrado das regiões depende basicamente de: disciplina científica, técnica administrativa adequada e abordagem interdisciplinar e global.

No caso de Distrito Federal, a Região Integrada de Desenvolvimento Econômico do Distrito Federal e Entorno (RIDE-DF), definhada atualmente pela Lei Complementar no 163 de junho 2018, e inclui, além do Distrito Federal, 29 (vinte e nove) municípios do Estado de Goiás e 04 (quatro) municípios do Estado de Minas Gerais.

Além disso, temos a legislação aprovada sobre o planejamento territorial do Distrito Federal: 1) O Plano Diretor de Ordenamento Territorial (PDOT); 2) O Zoneamento Econômico-Ecológico do Distrito Federal (ZEE-DF); 3) A Lei de Uso e Ocupação do Solo (LUOS); e 4) O Plano de Preservação do Conjunto Urbanístico de Brasília (PPCUB). Existem ainda algumas tratativas governamentais indicam uma evolução, nos últimos anos sobre o assunto.

Algumas das tratativas bem relevantes e na agenda executiva do primeiro escalão do governo, por exemplo, o Novo plano de desenvolvimento econômico, (novo plano de desenvolvimento econômico), uma política pública que pretende, nos próximos anos, implantar programas, projetos e ações que fomentem exatamente a transformação da Região metropolitana de Brasília numa área nacional relevante de atração de investimentos produtivos.

$\mathrm{RC}: 93520$

Disponível em: https://www.nucleodoconhecimento.com.br/ciencias-sociais/atracaode-investimentos 
Essa política de Atração de Investimentos (Al) tem sido positivada paulatinamente no âmbito do Distrito Federal. Os projetos de lei são: 1) Plano Distrital de (Al); 2) Criação da Agência de (Al) de Brasília; e 3) Política de Desenvolvimento Sustentável. Já as propostas de decreto do governo: 1) Grupo de Trabalho para elaboração do PL da Agência de (Al); 2) Grupo de Trabalho para elaboração do PL da Política de Desenvolvimento Produtivo; 3) Grupo de Trabalho para a regulamentação da Lei do ZEE-DF. Por fim as portarias da SDE/DF para: 1) A implantação do Programa de Atração de Investidores e Empreendedores nos Arranjos Produtivos Locais ou nos Arranjos Comerciais Locais no DF; e 2) Portaria para a divulgação da lista de APLs do Distrito Federal.

É importante ressaltar que o crescimento contínuo da economia é um fenômeno que teve início com Revolução Industrial, até o início do século XIX a atividade econômica não sofria grandes variações, como observa Maddison (2001). Segundo o autor, o PIB per capita do mundo se manteve praticamente estacionário nos primeiros mil anos da nossa era. Posteriormente, entre os anos 1000 e 1820, isto é, nos oito séculos subsequentes, esse PIB mundial aumentou teve um crescimento de $5 \%$ (cinco pontos percentuais) por cada século transcorrido. Já no período, seguinte, da análise do historiador econômico, constatou-se um crescimento astronômico, entre 1820 e 1998, do PIB mundial cresceu aproximadamente 1,3\% ao ano.

Nos períodos mais recentes, houve um crescimento ainda mais elevado, com taxas cada vez maiores, os chamados "milagres" econômicos. No século XX, Japão, Alemanha, o "milagre" do Brasil e dos "tigres" asiáticos (Coreia do Sul, Taiwan, Singapura, Hong Kong), outros países do Leste Asiático e, mais recentemente, a China, o Vietnam, e a Índia, taxas próximas a 10\% (dez pontos percentuais) ao ano.

Até o início do século XIX, conforme relata Maddison (2001), tanto a população quanto o PIB mundial estavam estagnados. A partir desse período, o PIB mundial cresceu mais do que a população, com isso, em função do acúmulo de capital físico, houve o aumento do produto per capita.

RC: 93520

Disponível em: https://www.nucleodoconhecimento.com.br/ciencias-sociais/atracaode-investimentos 
As teorias convencionais (neoclássicas) explicam que a produção econômica está diretamente relacionada aos "fatores de produção", basicamente a força de trabalho e o capital físico (capital e trabalho). Contudo, a evidência empírica mostra que os rendimentos marginais dos fatores são decrescentes. Isto significa que, à medida que o estoque de um dos fatores aumenta, o mesmo incremento na quantidade empregada do mesmo tem um efeito cada vez menor na produção.

Se o estoque de força de trabalho é limitado pelo crescimento populacional e os rendimentos marginais do capital são decrescentes, então o crescimento econômico se aproximará de um "steady state" ou estado estacionário em que o crescimento do produto se iguala àquele da população, tendendo a zero na maior parte do mundo.

O emprego cada vez maior dos fatores de produção tem sido muito importante nas fases iniciais do crescimento econômico. São exemplos empíricos Inglaterra e Estados Unidos no século XIX, o Brasil e a China na segunda metade do século XX.

Durante esses períodos, incorporaram-se mão de obra na economia e os processos de industrialização foram acompanhados por investimentos em capital físico e em infraestrutura. Acontece que esse tipo de "crescimento extensivo", resultado do aumento no emprego dos fatores de produção, atualmente é um modelo esgotado.

Contudo, observamos que o crescimento econômico continua, mesmo que o modelo estivesse aparentemente esgotado, de acordo com Schultz (1972) a taxa de crescimento dos principais recursos não capturava o crescimento da produção que estava sendo observada porque temos utilizado medidas do capital e do trabalho que foram refinadas de maneiras a excluir muitas das melhorias que têm sido realizadas na qualidade desses recursos.

Para formalizar este crescimento não explicado, surgiu a teoria do crescimento endógeno e o conceito de produtividade total dos fatores, PTF, definido como a diferença entre o crescimento observado e o crescimento dos fatores da produção. De acordo com Romer $(1986,1992)$, por intermédio da Pesquisa e Desenvolvimento 
(P\&D) ou por políticas públicas de inovação, a inovação é o elemento central para explicar o crescimento econômico no longo prazo, como as ideias são bens não rivais, isto é, bens cuja disponibilidade não diminui quando utilizados por determinados produtores, explicam-se como os rendimentos marginais podem ser não decrescentes. Com a nova teoria do crescimento endógeno surgem conceitos como: capital humano e economia criativa.

\section{METODOLOGIA}

Realizou-se uma pesquisa entre os meses de maio e julho de 2019 com uma amostra eletiva de alguns representantes, da sociedade, do setor privado e do governo para investigar a percepção deles sobre o, Novo Plano de Desenvolvimento Econômico. Para realizar a pesquisa, fizemos uma análise de dados primários, mediante aplicação de um questionário (com escala liker), junto aos representantes envolvidos com o desenvolvimento socioeconômico da região de Brasília, por intermédio de uma escolha eletiva da amostra.

Essa é uma análise qualitativa de dados primários para identificar a percepção desses atores sobre essa política pública que está sendo formulada em Brasília para minimizar os impactos dos aspectos negativos do problema econômico identificado pela pesquisa, crescimento acelerado associado à estagnação do PIB nos últimos anos. As perguntas foram idealizadas com base nos fundamentos propostos por esse Novo Plano. A pesquisa avaliou preliminarmente a percepção desses autores sobre dois aspectos: (1) a maturidade das políticas públicas de atração de investimentos; e (2) a assertividade do governo com o novo plano de desenvolvimento econômico com foco em atração de investimentos.

A fim de buscar a cooperação de diferentes atores do Distrito Federal, foram encaminhados os questionários (para diferentes órgãos, entidades e representações da sociedade civil), de avaliação da percepção como amostra eletiva conforme preconiza o método de análise qualitativa. Os questionários foram 
encaminhados de maneira eletrônica por meio de ofício utilizando-se da máquina pública para envio, também enviou de maneira física a versão impressa do mesmo documento. Dessa maneira, colheu-se a percepção sobre o que está sendo produzido, no que se refere a: ações, projetos, programas e planos relacionados a essa política pública de atração de investimentos produtivos.

O questionário se dividia em três partes: (a) avaliação dos eixos temáticos propostos; (b) avaliação da percepção eficiência do trabalho feito; e (c) concordância com os eixos.

\section{RESULTADOS}

Das 24 (vinte e quatro) instituições que receberam o questionário: 14 (quatorze) responderam e 10 (dez) não enviaram suas respostas. Os eixos apontados como prioritários no questionário tiveram boa aceitação por mais de $90 \%$ dos que responderam. $\mathrm{O}$ índice de rejeição observado é praticamente nulo. Como podemos observar a seguir:

\section{(1) Melhoria do ambiente de negócios:}

A partir da escala contínua de ( 0 a 5), 92,8\% (noventa e dois vírgula oito, pontos percentuais), dos que responderam o questionário, atribuíram valores superior a 4 (quatro) no quesito eficiência do novo plano de desenvolvimento econômico:

1. $71,4 \%(5,0)$

2. $21,4 \%$ (de 4,0 a 4,9 )

3. $0 \% \quad($ de 3,0 a 3,9$)$

4. $7,2 \% \quad$ (de 2,0 a 2,9$)$

5. $0 \% \quad$ (de 1,0 a 1,9$)$

6. $0 \% \quad($ de 0,0 a 0,9$)$ 


\section{(2) Melhorias na infraestrutura logística:}

A partir da escala contínua de ( 0 a 5), 92,8\% (noventa e dois vírgula oito, pontos percentuais), dos que responderam o questionário, atribuíram valores superior a 4 (quatro) no quesito eficiência do novo plano de desenvolvimento econômico:

1. $64,3 \%(5,0)$

2. $28,5 \%$ (de 4,0 a 4,9 )

3. $0 \% \quad$ (de 3,0 a 3,9$)$

4. $0 \% \quad$ (de 2,0 a 2,9$)$

5. $0 \% \quad$ (de 1,0 a 1,9$)$

6. $7,2 \%$ (de 0,0 a 0,9$)$

\section{(3) Eficiência:}

A partir da escala contínua de (0 a 5) 100\% atribuíram valores superiores a 03 (três) no quesito eficiência do novo plano de desenvolvimento econômico:

1. $35,6 \%(5,0)$

2. $42,9 \%$ (de 4,0 a 4,9 )

3. $21,5 \%$ (de 3,0 a 3,9$)$

4. $0 \% \quad$ (de 2,0 a 2,9$)$

5. $0 \% \quad($ de 1,0 a 1,9$)$

6. $0 \% \quad($ de 0,0 a 0,9$)$

\section{(4) Diretrizes:}

Com uma escala contínua de ( 0 a 5 ) onde zero representa discordância total e cinco concordância total, $100 \%$ concordaram com as diretrizes apresentadas como relevantes pelo Novo Plano De Desenvolvimento Econômico.

1. $64,3 \% \quad(5,0)$

2. $28,5 \%$ (de 4,0 a 4,9$)$

RC: 93520

Disponível em: https://www.nucleodoconhecimento.com.br/ciencias-sociais/atracaode-investimentos 
3. $7,2 \%($ de 3,0 a 3,9$)$

4. $0 \% \quad$ (de 2,0 a 2,9 )

5. $0 \%$ (de 1,0 a 1,9$)$

6. $0 \% \quad($ de 0,0 a 0,9$)$

Com o questionário aplicado se pretendeu capturar a percepção inicial da amostra de alguns agentes relevantes (representando entidades do governo e pesquisadores independentes) sobre os seguintes temas: 1) O nível de maturidade das políticas públicas voltadas para o desenvolvimento socioeconômico, em Brasília nos últimos tempos; 2) O grau importância de uma política pública específica para esse fim; e 3) A satisfação com relação as diretrizes do Plano de Desenvolvimento Econômico com foco em Atração de Investimentos Produtivos

Quanto ao nível de maturidade das políticas públicas existentes, há indícios que não tem sido satisfatória perante a amostra. A alta avaliação em quesitos como melhoria do ambiente de negócios e da infraestrutura mostra que esses eixos não estão sendo bem trabalhados. Outro tipo de desafio nas políticas existentes, e que divide opiniões dentre os agentes interessados, é a concessão de subsídios e incentivos do governo, coisa que o GDF não tem histórico de ser bem-sucedida. A ineficiência dos incentivos desenhados pelos programas de desenvolvimento existentes atualmente foi apontada como parte do descontentamento por alguns entrevistados.

Quanto a necessidade da criação de um novo modelo de desenvolvimento para a região metropolitana de Brasília, pareceu ser bem aceita nessa pesquisa inicial. Dentre as diretrizes que são consenso entre os agentes está a infraestrutura e melhoria de ambiente de negócios. Mas outras questões, como a escolha dos setores da economia ou quais cadeias produtivas a serem desenvolvidos; bem como a estratégia, por exemplo a já citada concessão de benefícios, ainda não são consenso entre os agentes e carecem de mais estudo da parte do governo para serem elaborados.

RC: 93520

Disponível em: https://www.nucleodoconhecimento.com.br/ciencias-sociais/atracaode-investimentos 


\section{CONCLUSÃO}

Diante do problema socioeconômico apresentado, o possível colapso socioeconômico, ceteris paribus, a partir do dilema discutido pela pesquisa e da política pública corretiva apresentada, o Novo plano de desenvolvimento econômico com forco em atração de investimentos que pretende transformar Brasília numa área nacional de destino de investimentos produtivos, formulou-se o questionário para setores envolvidos no processo.

De acordo com o resultado do questionário de uma amostra eletiva, para os representantes do setor produtivo, da sociedade civil e do governo, a política pública denominada, Novo plano de desenvolvimento econômico, que está sendo formulada a partir da identificação de um problema socioeconômico da região metropolitana de Brasília, com a finalidade de transforma-la numa área de nacional de atração de investimentos produtivos, é bastante assertiva, segundo eles.

Observa-se que Brasília é uma região que tem algumas características propícias para se tornar uma região nacional de interesse para atração de investimentos produtivos, conforme demonstra os estudos técnicos e os dados secundários, apontados nesse artigo.

Essa pesquisa captura apenas a opinião de especialistas sobre o início da elaboração de um plano de desenvolvimento, a fim de verificar se a direção sendo tomada é satisfatória. Além do embasamento teórico, jurídico e estudos de casos necessários para a criação de um novo modelo de desenvolvimento para Brasília, será necessário ouvir mais vezes as partes interessadas. Ou seja, conforme o plano amadurece se faz necessário consultar o setor produtivo, assim como a academia, com intuito de adequar as propostas a realidade.

Além disso, do ponto de vista da maturidade das políticas públicas específicas para atração de investimentos produtivos, segundo os resultados do questionário 
revelam, para os que responderam, um nível bom de maturidade de acordo com os resultados da pesquisa.

\section{REFERÊNCIAS}

ANTERO, Cecilia Alves da Silva; RODRIGUES, Cristiana Tristão; EMMENDOERFER, Magnus Luiz; DALLABRIDA, Valdir Roque. Política Pública de apoio ao desenvolvimento de APLs uma análise do impacto em Minas Gerais, Brasil. Cadernos Ebape.Br, [S.L.], v. 18, n. 1, p. 61-73, jan. 2020. FapUNIFESP (SciELO). http://dx.doi.org/10.1590/1679-395176924.

CARVALHO, Rogério Galvão de. Et al. Política pública de atração de investimentos em Brasília: erros e acertos. Revista Científica Multidisciplinar Núcleo do Conhecimento. Ano 06, Ed. 02, Vol. 01, pp. 21-59. Fevereiro de 2021.

COOPER, RICHARD N. MADDISON, ANGUS. The World Economy: A Millennial Perspective. Foreign Affairs, v. 80, n. 6, p. 176, 2001.

LASTRES, HELENA M. M. CASSIOLATO, JOSÉ EDUARDO. Inovação e sistemas de inovação: relevância para a área de saúde. RECIIS, v. 1, n. 1, 2007.

LEME, Paulo Henrique Montagnana Vicente; AGUIAR, Bruno Henrique; REZENDE, Daniel Carvalho de. A convergência estratégica em Arranjos Produtivos Locais: uma análise sobre a cooperação entre atores em rede em duas regiões cafeeiras. Revista de Economia e Sociologia Rural, [S.L.], v. 57, n. 1, p. 145-160, jan. 2019. FapUNIFESP (SciELO). http://dx.doi.org/10.1590/1234-5678180694790570109.

LIMA, Jacob Carlos. A globalização periférica e a ressignificação dos lugares. Sociedade e Estado, [S.L.], v. 35, n. 3, p. 765-786, dez. 2020. FapUNIFESP (SciELO). http://dx.doi.org/10.1590/s0102-6992-202035030005. 
LOCAL, APL. [PDF] APL ARRANJO PRODUTIVO LOCAL - Free Download PDF.

Silo.tips. Disponível em: <https://silo.tips/download/apl-arranjo-produtivo-local>. Acesso em: 7 jun. 2020.

Mapa de APLs. Redesist.ie.ufrj.br. Disponível em: <http://www.redesist.ie.ufrj.br/atividades/mapa-de-apls>. Acesso em: 7 jun. 2020.

MARSHALL, ALFREDWHITAKER, JOHN K. The correspondence of Alfred Marshall, economist, Volume 2, At the summit, 1891-1902. [s.l.: s.n., s.d.].

MASAHISA, FUJITATHISSE, JACQUES-FRANÇOIS. The new economic geography: a selective survey. [S.I.]: [s.n.], 1998.

PAULINO, Ana Elisa Lara. O impacto do "milagre econômico" sobre a classe trabalhadora segundo a imprensa alternativa. Revista Katálysis, [S.L.], v. 23, n. 3, p. 562-571, dez. 2020. FapUNIFESP (SciELO). http://dx.doi.org/10.1590/1982$02592020 v 23 n 3 p 562$.

PORTER, MICHAEL, MAGRETTA, JOANKRAMER, MARK R. Strategy and Competition. Boston: Perseus Book LLC (Ingram), 2014.

ROMER, PAUL. Cake Eating, Chattering, and Jumps: Existence Results for Variational Problems. Econometrica, v. 54, n. 4, p. 897, 1986.

SCHULTZ, THEODORE W. Human resources [by Theodore W. Schultz]. New York: National Bureau of Economic Research, 1972.

STOUGH, ROGER, KARLSSON, CHARLIEJOHANSSON, BÖRJE. Entrepreneurship and regional development. Northampton, MA: Edward Elgar Pub., 2010.

Enviado: Junho, 2021. 
Aprovado: Agosto, 2021.

RC: 93520

Disponível em: https://www.nucleodoconhecimento.com.br/ciencias-sociais/atracaode-investimentos 